\title{
Re-canalization in acute ischemic stroke: The strategies
}

Jeyaraj Durai Pandian

Department of Neurology, Stroke Unit, Betty Cowan Research and Innovation Centre, Christian Medical College, Ludbiana - 141 008, Punjab, India

Address for correspondence: Prof. J eyaraj Durai Pandian, Department of Neurology, Stroke Unit, Betty Cowan Research and Innovation Centre, Christian Medical College, Ludhiana - 141 008, Punjab, India. E-mail: jeyarajpandian@ hotmail. com

DOI: $10.4103 / 0028-3886.48804$

\begin{abstract}
Thrombolytic stroke therapy is based on the "re-canalization hypothesis," i.e., that reopening of occluded vessels improves clinical outcome in acute ischemic stroke through regional reperfusion and salvage of threatened tissues. Re-canalization is an important predictor of stroke outcome in all the modalities of thrombolysis. Thrombolysis in acute ischemic stroke evolved from clinical trials with intravenous (IV) tissue plasminogen activator (tPA) to combination treatments with Intra-arterial (IA)/mechanical reperfusion techniques. The combined approach reduces time to initiation of treatment and may increase re-canalization and chances of a good clinical outcome. In IV thrombolysis overall re-canalization rate is $46.2 \%$ during the first $6-24 \mathrm{hrs}$. Intra-arterial thrombolysis has higher early re-canalization rate, $63.2 \%$. The highest re-canalization rate is seen with mechanical thrombolysis, $83.6 \%$. 0 ther factors in addition to re-canalization: stroke severity, older age, systolic hypertension, location of arterial occlusion, collateral blood supply, and time from stroke onset to treatment play an important role in determining the clinical outcome following thrombolysis with tPA. Future trials should look at the interplay of various factors like re-canalization, reperfusion, and collateral flow and clot burden in the evaluation of reperfusion therapies in acute ischemic stroke.
\end{abstract}

Key words: Intraarterial, intravenous, ischemic stroke, re-canalization, thrombolysis

\section{Introduction}

Over the last decade or so there have been rapid advances in the management of patients with acute ischemic stroke. Since the publication of the landmark trial, National Institute of Neurological Disorders and Stroke (NINDS) Study Group in 1995, a significant advance has taken place in the stroke thrombolysis. ${ }^{[1]}$ Intravenous (IV) recombinant tissue plasminogen activator (tPA) was approved for IV thrombolysis in acute ischemic stroke by the Food and Drug Administration, United States of America in 1996 and it represents the first scientifically proven reperfusion therapy. ${ }^{[2]}$ The success of reperfusion therapy depends on both the degree of achievement of re-canalization and also on the degree and timing of reperfusion relative to ongoing brain ischemia. ${ }^{[2]}$

Re-canalization of an occluded artery is the most effective treatment for acute ischemic stroke. ${ }^{[3]}$
Thrombolytic therapy in acute ischemic stroke is based on the "re-canalization hypothesis," reopening of occluded vessels improves clinical outcome through regional reperfusion and salvage of threatened tissues. ${ }^{[4]}$ Though this hypothesis is well accepted, it has also been challenged. ${ }^{[5]}$ Several biologic factors may weaken the relationship of re-canalization to outcome in patients with acute ischemic stroke. In large occlusive disease, re-canalization may not be effective because of distal embolization and microcirculatory occlusion (no reflow phenomenon). Re-canalization may occur too late to benefit ischemic tissue. Adequate collateral circulation may protect tissue even without re-canalization. Re-canalization may exacerbate tissue injury by promoting reperfusion injury, excessive cerebral edema, and hemorrhagic transformation. ${ }^{[4]}$

Intravenous and intra-arterial (IA) thrombolysis is widely practiced in many developed and developing countries. More stroke units are being set up in developing 
countries. ${ }^{[6]}$ The purpose of this article is to review the current understanding about re-canalization in acute ischemic stroke with particular reference to grading, re-canalization in various modes of thrombolysis, stroke outcomes and also the factors which may influence re-canalization.

\section{Re-canalization Grading}

\section{Arteriography}

The thrombolysis in myocardial infarction (TIMI) grading system is widely used in stroke thrombolysis studies [Table 1]. ${ }^{[7]}$ However the TIMI grading system has certain limitations when applied to assess re-canalization of intracranial arteries. The TIMI system evaluates local re-canalization and does not accurately reflect the dynamic nature of the re-canalization process during thrombolysis in ischemic stroke. ${ }^{[8]}$ By TIMI system, the phenomenon of proximal clot fragmentation followed by downstream embolization occluding smaller arteries cannot be adequately assessed. Higashida et al. ${ }^{[9]}$ proposed the thrombolysis in cerebral infarction (TICI) score, and adapted the original TIMI score for the cerebral circulation as assessed on conventional angiography [Table 1]. Mori proposed a classification looking at four degrees of reperfusion as seen on arteriography [Table 1]. ${ }^{[10]}$ Mori's classification divides

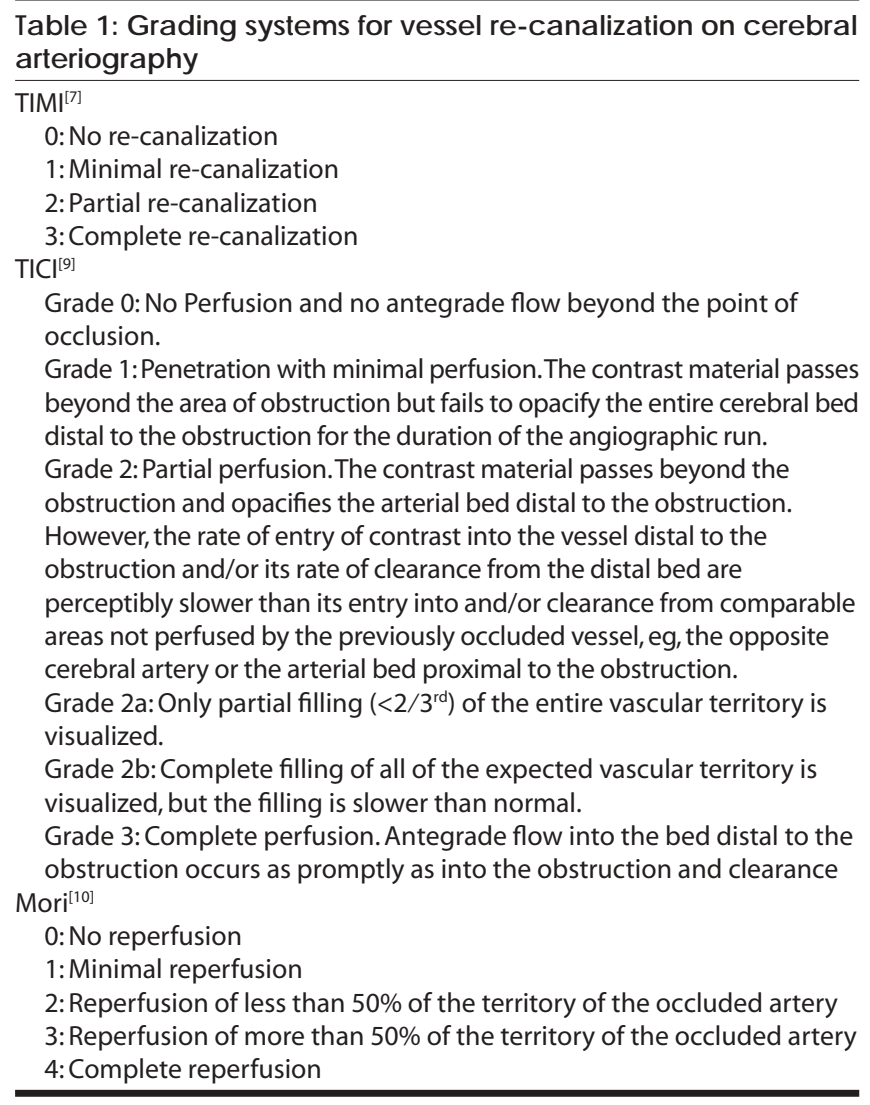

Classification by Mori and coworkers ${ }^{[10]}$; TIMI, thrombolysis in myocardial infarction ${ }^{[7]}: \mathrm{TICl}$-thrombolysis in cerebral infarction ${ }^{[9]}$, Mori large proportion of patients with partial reperfusion into two groups, Mori grade 2: reperfusion less than $50 \%$ of the territory of the occluded artery and Mori grade 3: reperfusion of more than $50 \%$.

Arnold and his colleagues evaluated the outcome in patients with M1 or M2 segment occlusion of the middle cerebral artery (MCA) using TIMI and Mori grading systems. ${ }^{[11]}$ No difference in the outcome was observed between the two grading systems when re-canalization or reperfusion was missing, minimal, or complete. In patients with partial re-canalization or reperfusion the outcome assessment was more refined with Mori grading system than with TIMI grading. If re-canalization or reperfusion is used as a surrogate marker in the stroke outcome trials, Mori grading gives additional information to the widely used TIMI classification.

\section{Magnetic resonance angiography}

Neumann-Haefelin and coworkers ${ }^{[12]}$ used time of flight magnetic resonance angiography (MRA) to assess re-canalization rates in patients with acute ischemic stroke following IV thrombolysis. Outcomes were better in patients with TIMI 1 than in patients with TIMI 0 , there by suggesting that even minimal early re-canalization might be beneficial in some patients following thrombolysis. Time of flight MRA may not be sensitive enough to pick up the slow flow, which can be visible on digital subtraction angiography (DSA), DSA TIMI 1 might correspond to MRA TIMI 0 and MRA TIMI 1 might correspond to DSA TIMI 2.

\section{Transcranial Doppler}

Demchuk and colleagues ${ }^{[13]}$ studied re-canalization and outcomes following IV thrombolysis using transcranial Doppler. Re-canalization was assessed using brain ischemia (TIBI) flow-grading system. TIBI waveforms were graded as: 0-absent; 1-minimal; 2-blunted; 3-dampened; 4-stenotic; and 5-normal. Pre-treatment National Institute of Health Stroke Scale (NIHSS) scores were higher in patients with TIBI grade 0 . TIBI flow improvement to grade 4 or 5 occurred in $35 \%$ of patients with an initial grade of 0 or 1 , and in $52 \%$ with initial grade 2 or 3 . The 24-hour NIHSS scores were higher in the follow-up in patients with TIBI grade 0 or 1 . TIBI classification correlated well with initial stroke severity, clinical recovery, and mortality in IV tPA treated patients. A flow-grade improvement correlated with clinical improvement.

\section{Reperfusion Strategies - Re-canalization Rates}

IV thrombolysis

In all the major IV thrombolysis randomized trials, neither 
the vessel status (occlusion) nor the re-canalization status was assessed..$^{[1,14-17]}$ In the recent meta-analysis, the overall re-canalization rate with any intervention was $55 \%$. In patients who received IV thrombolysis the re-canalization rate was $46.2 \%$. Spontaneous re-canalization rate within $24 \mathrm{~h}$ was $24.1 \%{ }^{[4]}$ The meta-analysis also analyzed the re-canalization rates in specific target vessels. Recanalization rate across all the vessels was $58.9 \%$. For MCA/anterior cerebral artery (ACA), it was 61\% (spontaneous 22\%, IV 54.7\%, IA 66.5\%, combined IV/IA $66.6 \%$, and mechanical 78\%). For posterior circulation vessels, it was $66.2 \%$ (IV 80\% (4/5), IA 63\% (73/115), combined IV/IA 67\% (2/3), and mechanical 100\% (7/7)). Re-canalization rates were lower for internal carotid artery (ICA), 49.8\% (IV 14\% (5/36), IA 48.8\% (59/121), combined IV/IA 60.5\% (23/38), mechanical 77.8\% (14/18)).

The introduction of modern noninvasive imaging modalities has greatly facilitated the assessment of vessel status both in the hyperacute situation and during the first few days after symptom onset, obviating the need for repeated catheter angiography. ${ }^{[12]} \mathrm{MRA}$ is particularly useful since it is relatively easy to interpret and can be combined with other stroke MRI sequences such as diffusion- and perfusion weighted imaging, thus allowing a comprehensive assessment of tissue status. ${ }^{[18-24]}$

\section{Recent IV thrombolysis trials}

In the recent trials in addition to the re-canalization, greater emphasis is being laid on the reperfusion as an important outcome measure using the diffusionperfusion mismatch. Desmoteplase is a highly fibrin specific and non-neurotoxic thrombolytic agent. The efficacy and safety of this agent was studied in a randomized dose-finding trial, desmoteplase in acute ischemic stroke trial (DIAS), in patients with perfusiondiffusion mismatch on MRI done within 3 to $9 \mathrm{~h}$ of onset of stroke. ${ }^{[25]}$ Initially patients were randomized to fixed doses of IV desmoteplase $(25 \mathrm{mg}, 37.5 \mathrm{mg}$, or $50 \mathrm{mg}$ ) or placebo. As the observed rate of symptomatic intracranial hemorrhage was in excess, lower weightadjusted doses $(62.5 \mu \mathrm{g} / \mathrm{kg}, 90 \mu \mathrm{g} / \mathrm{kg}$, and $125 \mu \mathrm{g} / \mathrm{kg})$ were subsequently investigated. Reperfusion was assessed 4 to $8 \mathrm{~h}$ post-treatment and defined as either $\geq 30 \%$ reduction of mean transit time (MTT) volume or $\geq 2$ point improvement in TIMI grading scheme on the MRA. Early reperfusion correlated favorably with clinical outcome $(52.5 \%$ vs. $24.6 \%)(P<0.002)$.

The efficacy and safety of IV desmoteplase was further studied in a randomized dose-escalation study, dose escalation of desmoteplase in acute stroke (DEDAS), in patients who presented within 3 to $9 \mathrm{~h}$ stroke onset. ${ }^{[26]}$ Eligibility criteria included baseline NIHSS scores of 4-20 and MRI evidence of perfusion/diffusion mismatch. Reperfusion was defined as either $\mathrm{a} \geq 30 \%$ reduction of
MTT volume of abnormality or $\geq 2$ point improvement on the TIMI scale on MRA. The results of DEDAS were consistent with the results of DIAS. At a dose of $125 \mu \mathrm{g} /$ $\mathrm{kg}$ desmoteplase appeared to improve clinical outcome, especially in patients fulfilling all MRI criteria DIAS2, a phase III study, was done to confirm the results of the DIAS/DEDAS studies and also to investigate the clinical efficacy and safety of desmoteplase in patients with acute ischemic stroke with tissue at risk, as assessed by MR PI-DWI or perfusion CT. ${ }^{[27]}$ Patients were randomly assigned in 1:1:1 ratio to desmoteplase, or placebo within 3-9 h of symptom onset. Mismatches were evaluated qualitatively, difference between core and perfusion lesions, according to the local practices at each site. TIMI criteria were adopted while assessing the vessel patency. The median baseline NIHSS score was 9 (IQR 6-14), and only $30 \%$ of the patients had a visible occlusion of a vessel at presentation. The core lesion and the mismatch volumes were small (median volumes were $10.6 \mathrm{~cm}^{3}$ and $52.5 \mathrm{~cm}^{3}$, respectively). The DIAS-2 study failed to show a benefit of desmoteplase given 3-9 h after the onset of stroke. The high response rate observed in the placebo group may be related to low baseline NIHSS scores, small core lesions, and small mismatch volumes. These variables possibly reduced the potential to detect any effect of desmoteplase.

The diffusion and perfusion imaging evaluation for understanding stroke evolution (DEFUSE) study was designed to test the hypothesis that IPA treated patients with a mismatch who had early reperfusion would have a significantly higher rates of "favorable clinical response" than mismatch patients who did not have early reperfusion. ${ }^{[28]}$ DEFUSE was a prospective study in patients with ischemic stroke within 3 to $6 \mathrm{~h}$ of symptom onset. MRI was done before and 3 to $6 \mathrm{~h}$ after IV tPA. Early reperfusion required a $30 \%$ or greater and $10 \mathrm{ml}$ or more reduction in PWI lesion volume on the 3- to 6-hour follow-up scan. The "favorable clinical response" rate was defined as the proportion of patients with a NIHSS score of 0 to 1 or 8 point decrease from the base line at 30 days follow-up. The "Mismatch" profile was defined as a PWI lesion that was $10 \mathrm{ml}$ or more and $120 \%$ or more of the DWI lesion. The "Small Lesion" profile was defined as a DWI and PWI volume both less than $10 \mathrm{ml}$. The "No Mismatch" profile was defined as a PWI volume less than $120 \%$ of the DWI lesion volume (patients with the small lesion profile excluded). The malignant profile was empirically defined as a baseline DWI lesion $100 \mathrm{ml}$ or more and/or a PWI lesion of $100 \mathrm{ml}$ or more with 8 seconds or longer of Tmax delay. Re-canalization was assessed by MRA as (1) normal, (2) decreased flow, (3) occluded, or (4) technically inadequate. The early followup MRAs (3-6h after tPA bolus) were compared with the baseline MRA in an unblinded fashion to determine whether partial or complete re-canalization had occurred. 
Complete re-canalization was defined as a change from occluded to normal or decreased flow to normal. Partial re-canalization was defined as a change from occlusion to decreased flow. Early reperfusion was associated with significantly increased odds of achieving a favorable clinical response in patients with a perfusion/diffusion mismatch (odds ratio, 5.4; $\mathrm{P}<0.03$ ) and an even more favorable response in patients with the target mismatch profile (odds ratio, 8.7; $\mathrm{P}<0.01$ ). Patients with the no mismatch profile did not appear to benefit from early reperfusion. Early reperfusion was associated with fatal intracranial hemorrhage in patients with the malignant profile.

The echoplanar imaging thrombolytic evaluation trial (EPITHET) was a phase II prospective, randomized, double-blinded, placebo-controlled trial in patients with acute ischemic stroke who were imaged with serial echoplanar MRI and treated with IV tPA or placebo within 3-6 ho of stroke onset. ${ }^{[29]}$ Standardized DWI, PWI, and MRA sequences were obtained before treatment and repeated at day $3-5$. Reperfusion was defined as $>90 \%$ reduction between baseline and day 3 PWI volumes. At baseline and day $3-5$, the presence and degree of arterial obstruction in major intracerebral vessels were assessed using the TIMI scale. Re-canalization was defined as improvement of TIMI grading from baseline to day 3-5 arterial occlusion by $\geq 2$ points. Reperfusion was more frequent with tPA than with placebo and was associated with less infarct growth $(P=0.001)$, better neurological outcome $(P<0.0001)$, and better functional outcome $(P=0.010)$ than was no reperfusion.

In summary with IV thrombolysis overall re-canalization rates vary from $30 \%$ to $92 \%$ during the first $6-24 \mathrm{~h}^{[30]}$ The temporal profile of re-canalization during the first $6 \mathrm{~h}$ after IV tPA shows a high rate of re-canalization during the first hour (45\%), with only limited additional re-canalization during the second hour (11\%) and up to $6 \mathrm{~h}(7 \%))^{[31]}$ Re-canalization rates may vary depending on the site of occlusion and are lower in proximal than in distal occlusions, partly reflecting differences in clot burden. IV tPA may re-canalize only $10 \%$ of distal carotid occlusions and complete re-canalization of proximal MCA1 occlusion occurs in only 33\% of patients. ${ }^{[3]}$ Low rates of re-canalization have also been found in patients with coexisting carotid artery disease and with diabetes mellitus. ${ }^{[30]}$

\section{IA thrombolysis}

Compared with IV administration, IA tPA treatment offers potential advantages such as higher concentrations of tPA infused close to or into the clot, reduced systemic exposure to tPA and the possibility of mechanical disruption to facilitate thrombolysis. In open clinical series, IA thrombolysis has shown higher early re- canalization rates (50\% to $80 \%)$ than IV therapy (30\% to $50 \%) .{ }^{[3]}$ The only IA randomized trial, Prolyse in acute cerebral thromboembolism II (PROACT II) trial, showed substantial benefit of treatment initiated up to $6 \mathrm{~h}$ after onset of an MCA M1 or M2 occlusion. ${ }^{[32]}$ The re-canalization rate was significantly higher in the prourokinase group than in the control group $(66 \%$ vs $18 \%, \mathrm{P}<0.001)$. Despite a higher rate of symptomatic intracranial hemorrhages $(10 \%$ vs. $2 \%)$, the rate of favorable outcome (modified Rankin scale (mRS) 0-2 at 90 days) was significantly higher in patients given prourokinase than in those given placebo (40\% vs. $25 \%$, $P=0.04$ ). Similar efficacy and safety profiles for IA treatment were described in many studies mostly case series. IA tPA may therefore be an option in select patients with large vessel occlusions, These patients have a limited response to IV tPA. Although re-canalization rates probably are higher with IA thrombolysis, the clinical benefit may be reduced by the time delay in initiation of the procedure and by the time necessary for chemical clot lysis. ${ }^{[3]}$

\section{Combined IV and IA Thrombolysis}

In the interventional management of stroke (IMS) study, patients with NIHSS score of $>10$ were treated initially with $0.6 \mathrm{mg}$ of IV tPA followed by IA tPA (upto $22 \mathrm{mg}$ ). ${ }^{[33]}$ Partial or complete re-canalization was achieved in 64\% of patients after IA treatment. Compared with historical controls treated with IV IPA, the IV and IA tPA treated patients showed only a modest trend to improved clinical outcomes. In a recent meta-analysis re-canalization rate of combined IV and IA thrombolysis did not significantly differ from IA alone $(67.5 \%$ vs. $56 / 83 ; \mathrm{P}<0.45) .{ }^{[4]}$

\section{Mechanical thrombolysis}

Endovascular mechanical methods to achieve re-canalization offer several distinct advantages over endovascular pharmacological thrombolysis. Mechanical therapies may achieve re-canalization within a few minutes rather than up to 120 min required with IA thrombolysis. ${ }^{[3]}$ They are more effective in removing large thrombi in proximal vessels, may be more efficacious at achieving full re-canalization and are associated with lower hemorrhage risk by eliminating exposure to thrombolytic agents. Disadvantages include bulky catheters, risk of endothelial damage, vessel wall perforation and intracranial bleeding. ${ }^{[3]}$ Endovascular mechanical methods comprise a wide range of mechanical devices designed to mechanically retrieve, fragment or obliterate thromboemboli, atherosclerotic plaque and other vascular occlusions. ${ }^{[34,35]}$

The mechanical embolus removal in cerebral ischemia (MERCI) trial is a single arm trial to study the safety and technical efficacy of mechanical embolus removal. 
Patients with ICA, M1 or M2-MCA, VA and BA occlusion were treated within $8 \mathrm{~h}$ of onset. ${ }^{[36]}$ The median baseline NIHSS score was 19 . Overall re-canalization was achieved in $46 \%$ of patients in intention to treat analysis. Clinically significant procedural complications occurred in $7.1 \%$ of patients, symptomatic intracranial bleeding in $5 \%$ and overall mortality was $44 \%$. Favorable outcome $(\mathrm{mRS} \leq 2)$ at 90 days was more frequent in patients with successful re-canalization when compared to patients without ( $46 \%$ vs. $10 \%$; $P<0.0001)$.

In a systematic review of studies of clot removal devices (laser, rheolytic, aspiration, coil, snare and ultrasonic devices) in acute ischemic stroke ${ }^{[37]}$ the distribution of arterial occlusion was MCA in 40\%, ICA in $20 \%$ and posterior circulation in $39 \%$. Patients had a preprocedure median NIHSS score of 21. The clot was accessible in $85 \%$ of patients. Re-canalization was achieved in 68\% and any type of hemorrhage occurred in $23 \%$. Of the accessible patients, $29 \%$ died and $34 \%$ had a favorable outcome at 90 days. Mechanical embolectomy appears to confer both survival and functional outcome advantages when compared with no intervention.

\section{Combined pharmacological and endovascular treatment}

Early experience with endovascular interventions suggests that combined pharmacological and mechanical therapies are more often required to achieve optimum reperfusion, more so in patients with large vessel stroke. ${ }^{[38]}$ The main concern of a combined approach is the hemorrhagic complications. The IMS trial showed that IV tPA followed by IA tPA carries an acceptable risk with an intracranial bleeding rate similar to to IV tPA treated patients. ${ }^{[33]} \mathrm{A}$ combined approach might therefore have an acceptable safety and lead to higher re-canalization rates and better clinical outcome.

Multi MERCI was an international, multicenter, prospective, single-arm trial of thrombectomy in patients with large vessel stroke treated within $8 \mathrm{~h}$ of symptom onset. ${ }^{[39]}$ Patients with persistent large vessel occlusion after IV tPA treatment were included. Once the newer generation (L5 Retriever) device became available, investigators were instructed to use the L5 Retriever to open vessels and could subsequently use older generation devices and/or IA tPA. ${ }^{[39]}$ Re-canalization was defined as achieving TIMI II or III flow in all treatable vessels. The baseline median (interquartile range) NIHSS score was 19 (15 to 23). Treatment with the L5 Retriever resulted in successful re-canalization in $57.3 \%$ treatable vessels and in $69.5 \%$ after adjunctive therapy (IA tPA, mechanical). Overall, favorable clinical outcomes (mRS: 0 - 2) occurred in $36 \%$ and mortality was $34 \%$; both outcomes were significantly related to vascular re-canalization. ${ }^{[39]}$
The IMS II study was an open-labeled single-arm pilot study to determine the usefullness or lack thereof of the combined IV/IA therapy and low-energy sonography via the EKOS Primo sonography microcatheter at the site of the arterial occlusion in eligible patients with acute large ischemic strokes (NIHSS $\geq 10$ ) treated within $3 \mathrm{~h}$ of symptoms onset. ${ }^{[40]}$ Complete re-canalization occurred in $41.4 \%$ of sonography microcatheter-treated occlusions at 60 minutes. Complete re-canalization was achieved at $2 \mathrm{~h}$ or at the end of the procedure in $68.9 \%$ in the ultrasound catheter treated group. IMS II provides evidence that the EKOS Primo sonography microcatheter exhibits a trend toward improved re-canalization of the occlusion compared with a standard microcatheter.

The IMS III Study is designed to determine if clinical outcomes achieved with standard IV tPA treatment can be improved with a reduced dose of IV tPA plus a more aggressive IA re-canalization approach. ${ }^{[41]}$ The thrombectomy in unsuccessful stroke thrombolysis (THRUST) trial compares the effect of thrombectomy using the Merci Retriever vs. no intervention following unsuccessful IV thrombolysis (http://www.acutestroke. org). The THRUST study is part of the international collaboration Safe Implementation of thrombolysis in stroke (SITS). ${ }^{[42]}$ The MR re-canalization of stroke clots using embolectomy (MR-RESCUE) trial selects patients on the basis of diffusion over perfusion weighted imaging mismatch within an 8-h time window, providing a 'physiological tissue salvage window' in individual patients instead of a general time window for groups of patients. ${ }^{[43]}$

\section{Sonothrombolysis}

Experimental evidence suggests that thrombolytic effect of IV tPA is substantially enhanced by ultrasound, particularly if used in low $\mathrm{MHz}-\mathrm{kHz}$ frequency range. ${ }^{[44-46]}$ The exposure to ultrasound causes various changes in the blood clot such as reversible disaggregation of uncross linked fibrin fibres and microcavity formation in the shallow layers of thrombus. ${ }^{[44-46]}$ This increases penetration of tPA into the clot leading to residual flow enhancement with microstreaming and vessel dilation. ${ }^{[44-46]}$

In CLOTBUST phase II trial 126 patients were randomly assigned to receive continuous TCD monitoring or placebo in addition to IV tPA. ${ }^{[47]}$ Complete re-canalization or dramatic clinical recovery within $2 \mathrm{~h}$ after the administration of tPA bolus occurred in $49 \%$ in the target group as compared to $30 \%$ in the control group $(P=0.03)$. Only $4.8 \%$ patients developed symptomatic intracerebral hemorrhage. These results showed the positive effects of $2 \mathrm{MHz}$ continuous TCD monitoring in acute stroke, with no increase in the rate of intracerebral hemorrhage. ${ }^{[48]}$ In the TRUMBI trial, Daffertshofer 
et al. ${ }^{[48]}$ included 26 patients within the 6 -h time window in a multicenter clinical trial, 12 patients in tPA only group and 14 patients tPA plus 90 min of low frequency ( $300 \mathrm{kHz}$ ) ultrasound exposure group. The study had to be stopped prematurely due to an increased incidence of intracranial hemorrhages (tPA group-42\% vs. tPA plus ultrasound group 93\%). Parenchymal hemorrhages with subarachnoid extension or affecting normal brain tissue occurred in the combined treatment group. Potentially, reverberations of the long-wavelength ultrasound occurred inside the head, leading to hotspots in addition to the mechanical distortion of the brain microvessels with $\mathrm{kHz}$ frequencies. ${ }^{[48]}$

Microbubbles, previously known as diagnostic microbubbles or gaseous microspheres, were originally designed to improve conventional ultrasound images, facilitation of thrombolysis is now emerging as a new treatment application for this technology. ${ }^{[49]}$ Newer generation bubbles use specific phospholipid molecules that, when exposed to mechanical agitation, arrange themselves in nano-bubbles of consistent $1.2 \mu \mathrm{m}$ (or even lesser) diameter. When injected intravenously, nano-bubbles carry gas through the circulation. ${ }^{[49-51]}$ As the bubbles approach and permeate through the thrombus, they can be detected and activated by the ultrasound energy. Upon encountering an ultrasound pressure wave, the phospholipid shell breaks up and releases gas. The result is the bubble-induced cavitation with fluid jet that erode the thrombus surface. ${ }^{[49-51]}$ In the presence of tPA, this erosion increases the surface area for thrombolytic action and accelerates lysis of clots. ${ }^{[49-51]}$ Molina et al. first tested galactose-based air microbubbles (Levovist ${ }^{\circledR}$, Schering, Berlin, Germany), 2-MHz TCD, and IV tPA in humans with acute ischemic stroke. ${ }^{[52]}$ In a recently conducted pilot trial, higher re-canalization rates were seen with third-generation perflutren-lipid microspheres. The perflutren microspheres $(\mu \mathrm{S})$ reached and permeated beyond intracranial occlusions, with no increase in symptomatic hemorrhage after systemic thrombolysis. ${ }^{[53]}$

\section{Re-canalization and Stroke Outcome}

Clinical outcome in relation to re-canalization or no re-canalization was studied in a meta-analysis including 998 patients. ${ }^{[4]}$ Good outcome was achieved in $58.1 \%$ of patients with re-canalization and in $24.8 \%$ of patients with no re-canalization (odds ratio, 4.43; $95 \% \mathrm{CI}, 3.32$ to 5.91 ). In the subgroup of patients in whom re-canalization was assessed within $6 \mathrm{~h}$ of onset, good outcome was achieved in $50.9 \%$ of patients with re-canalization and in $11.1 \%$ of patients with no re-canalization (odds ratio, 6.36; 95\% CI, 3.32 to 12.17). ${ }^{[4]}$ The frequency of fatal outcomes was $14.4 \%$ in patients with re-canalization and it was $41.6 \%$ in patients with no re-canalization (odds ratio, 0.24; 95\%
CI, 0.16 to 0.35$)$. In the subgroup with re-canalization within $6 \mathrm{~h}$, fatal outcomes occurred in $12.1 \%$ of patients with re-canalization and in $41.1 \%$ of patients with no re-canalization (odds ratio, 0.22 ; 95\% CI, 0.10 to 0.51 ). Re-canalization is associated with a 4 - to 5 -fold increase in the odds of good final functional outcome and a 4- to 5 -fold reduction in the odds of death.

\section{Does Re-canalization Lead to Reperfusion?}

Re-canalization of the primary occlusive arterial lesion does not necessarily imply capillary reperfusion. ${ }^{[54]}$ Also, lack of re-canalization does not necessarily reflect absence of reperfusion. Among the 57 patients who did not achieve re-canalization in the DIAS trial, $24.6 \%$ achieved favorable clinical outcome after 90 days suggesting that reperfusion can occur in the absence of re-canalization. ${ }^{[25]}$ One possible explanation is retrograde collateral flow. Adequate collateral circulation may contribute to maintain tissue viability in the absence of complete re-canalization. ${ }^{[54]}$

Other factors in addition to re-canalization including stroke severity, older age, systolic hypertension, location of arterial occlusion, collateral blood supply, and time from stroke onset to treatment may play important role in determining clinical outcome in patients treated with tPA..$^{[8]}$ The beneficial effect of early restoration of cerebral blood flow on stroke outcome may be hampered in part by factors such as extent of irreversible brain injury before re-canalization, excessive glucose burden at the time of reperfusion, and blood pressure changes during thrombolysis. ${ }^{[8]}$

\section{Re-canalization and Clot Burden}

Vascular re-canalization rates vary depending on thrombus location with lower rates in proximal arteries. ${ }^{[4]}$ In anterior circulation stroke, response to thrombolysis and clinical outcomes have been best in patients with distal MCA occlusion and worst in terminal ICA occlusion. ${ }^{[4,55]}$ Suspected mechanisms include larger thrombus burden and impaired collateral blood flow..$^{[4,55]}$

Puetz et al. studied the clot burden in CT angiography (CTA) using a new grading system for the anterior circulation. They allotted major arteries 10 points for the presence of contrast opacification on CTA. ${ }^{[55]}$ Two points each were subtracted for absence of contrast opacification in the complete cross-section of any part of the proximal M1 segment, distal M1 segment or supraclinoid ICA and 1 point each for M2 branches, A1 segment and infraclinoid ICA. Partial filling defects suggesting stenosis or non-occlusive 
thrombus were rated as patent. A score of 10 indicates absence of a visible occlusion on CTA, a score of 0 indicates occlusion of all major intracranial anterior circulation arteries. The clot burden score (CBS) was assessed in 263 patients with anterior circulation stroke who had undergone CTA. Patients with lower CBS (i.e. higher thrombus burden) had higher baseline NIHSS scores and lower baseline ASPECTS. There was a significant correlation of lower CBS with lower ASPECTS (Spearman's $\rho=0.45, P<0.001$ ) and higher NIHSS scores (Spearman's $\rho=-0.50, \mathrm{P}<0.001$ ). Patients with higher CBS were more likely to have an independent functional outcome $(P<0.001)$. In contrast, mortality increased in patients with low CBS compared with patients with high CBS $(P<0.001)$. In logistic regression analysis, CBS was an independent predictor of good functional outcome in a graded fashion after adjustment for age, gender and presence vs. absence of thrombolytic therapy. Final infarct size was larger in patients with low compared with patients with high CBS $(P<0.001)$. Furthermore, patients with lower CBS were more likely to have hemorrhagic infarct transformation $(P<0.003)$ and parenchymal hematoma $(P<0.008)$ on follow-up scans. As an advantage over angiographic scores, CBS does not rely on invasive vascular imaging and is therefore readily available when trying to decide on the best treatment approach in individual patients. ${ }^{[55]}$

In conclusions, stroke thrombolysis has evolved from clinical trials of simple IV tPA to combination treatments with IA/mechanical reperfusion techniques. Re-canalization is a powerful predictor of outcome following thrombolysis using all modalities in acute ischemic stroke. Stroke centers vary widely in their practices all over the world. The choice of thrombolytic therapy will depend upon the local available infrastructure. IV tPA may be started at community hospitals before patients transfer to a comprehensive stroke centre, where endovascular re-canalization may be initiated. The combined approach thereby reduces time to initiation of treatment and may increase re-canalization and chances of good clinical outcome. ${ }^{[3]}$ Future trials should look at the interplay of various factors like re-canalization, reperfusion, and collateral flow and clot burden score in evaluation of reperfusion therapies in acute ischemic stroke.

\section{References}

1. NINDS National Institute of Neurological Disorders and Stroke Study Group. Tissue plasminogen activator for acute ischemic stroke. N Engl J Med 1995;333:1581-7.

2. Broderick J, Saver J. Introduction to reperfusion. Stroke 2008 in press.

3. Thomassen L, Bakke SJ. Endovascular reperfusion therapy in acute ischemic stroke. Acta Neurol Scand 2007;115:22-9

4. Rha JH, Saver JL. The impact of re-canalization on ischemic stroke outcome: A meta-analysis. Stroke 2007;38:967-73.

5. von Kummer R, Holle R, Rosin L, Forsting M, Hacke W. Does arterial re-canalization improve outcome in carotid territory stroke? Stroke 1995;26:581-7.

6. Durai Pandian J, Padma V, Vijaya P, Sylaja PN, Murthy JM. Stroke and Thrombolysis in developing countries. Int J Stroke 2007;2:17-26.

7. TIMI Study Group. The Thrombolysis in Myocardial Infarction (TIMI) trial: Phase I findings. N Engl J Med 1985;312:932-6.

8. Molina CA. Degree of arterial re-canalization: An end point for efficacy in future intravenous thrombolytic trials. Stroke 2004;35:114-5.

9. Higashida R, Furlan A, Roberts H, Tomsick T, Connors B, Barr J, et al. Trial design and reporting standards for intra-arterial cerebral thrombolysis for acute ischemic stroke. J Vasc Interv Radiol 2003;14:S493-4.

10. Mori E, Tabuchi M, Yoshida T, Yamadori A. Intracarotid urokinase with thromboembolic occlusion of the middle cerebral artery. Stroke 1988;19:802-12.

11. Arnold M, Nedeltchev K, Remonda L, Fischer U, Brekenfeld C, Keserue B, et al. Re-canalization of middle cerebral artery occlusion after intra-arterial thrombolysis: Different re-canalization grading systems and clinical functional outcome. J Neurol Neurosurg Psychiatry 2005;76:1373-6

12. Neumann-Haefelin T, du Mesnil de Rochemont R, Fiebach JB, Gass A, Nolte C, Kucinski T, et al. Effect of incomplete (spontaneous and postthrombolytic) re-canalization after middle cerebral artery occlusion: A magnetic resonance imaging study. Stroke 2004;35:109-15.

13. Demchuk AM, Burgin WS, Christou I, Felberg RA, Barber PA, Hill MD, et al. Thrombolysis in brain ischemia (TIBI) TCD flow grades predict clinical severity, early recovery and mortality in intravenous TPA treated patients. Stroke 2001;32:89-93.

14. Hacke W, Kaste M, Fieschi C, Toni D, Lesaffre E, von Kummer R, et al. Intravenous thrombolysis with recombinant tissue plasminogen activator for acute hemispheric stroke: The European Cooperative Acute Stroke Study (ECASS). JAMA 1995;274:1017-25.

15. Hacke W, Kaste M, Fieschi C, von Kummer R, Davalos A, Meier D, et al. Randomised double-blind placebo-controlled trial of thrombolytic therapy with Intravenous alteplase in acute ischaemic stroke (ECASS II): Second European-Australasian Acute Stroke Study Investigators. Lancet 1998;352:1245-51.

16. Clark WM, Wissman S, Albers GW, Jhamandas JH, Madden KP, Hamilton S. Recombinant tissue-type plasminogen activator (alteplase) for ischemic stroke 3 to 5 hours after symptom onset: The ATLANTIS Study: A randomized controlled trial, Alteplase Thrombolysis for Acute Noninterventional Therapy in Ischemic Stroke. JAMA 1999;282: 2019-26.

17. Hacke W, Kaste M, Bluhmki E, Brozman M, Dávalos A, Guidetti D, et al. Thrombolysis with alteplase 3 to 4.5 hours after acute ischemic stroke. N Engl J Med 2008;359:1317-29.

18. Summers PE, Jarosz JM, Markus H. MR angiography in cerebrovascular disease. Clin Radiol 2001;56:437-56

19. Baird AE, Warach S. Magnetic resonance imaging of acute stroke. J Cereb Blood Flow Metab 1998;18:583-609.

20. Beauchamp NJ Jr, Barker PB, Wang PY, vanZijl PC. Imaging of acute cerebral ischemia. Radiology 1999;212:307-24.

21. Neumann-Haefelin T, Moseley ME, Albers GW. New magnetic resonance imaging methods for cerebrovascular disease: Emerging clinical applications. Ann Neurol 2000;47:559-70.

22. Schellinger PD, Fiebach JB, Hacke W. Imaging-based decision making in thrombolytic therapy for ischemic stroke: Present status. Stroke 2003;34:575-83.

23. Schellinger PD, Fiebach JB, Jansen O, Ringleb PA, Mohr A, Steiner T, et al. Stroke magnetic resonance imaging within 6 hours after onset of hyperacute cerebral ischemia. Ann Neurol 2001;49:460-9.

24. Parsons MW, Barber PA, Chalk J, Darby DG, Rose S, Desmond PM, et al. Diffusion and perfusion-weighted MRI response to thrombolysis in stroke. Ann Neurol 2002;51:28-37.

25. Hacke W, Albers G, Al-Rawi Y, Bogousslavsky J, Davalos A, Eliasziw M, et al. The Desmoteplase in Acute Ischemic Stroke Trial (DIAS) 
A phase II MRI-based 9-hour window acute stroke thrombolysis trial with intravenous desmoteplase. Stroke 2005;36:66-73.

26. Furlan AJ, Eyding D, Albers GW, Al-Rawi Y, Lees KR, Rowley HA, et al. Dose Escalation of Desmoteplase for Acute Ischemic Stroke (DEDAS) evidence of safety and efficacy 3 to 9 hours after stroke onset. Stroke 2006;37:1227-31.

27. Hacke W, Furlan AJ, Al-Rawi Y, Davalos A, Fiebach JB, Gruber F, et al. Intravenous desmoteplase in patients with acute ischemic stroke selected by MRI perfusion-diffusion weighted imaging or perfusion CT (DLAS-2): A prospective, randomised, double-blind, placebo-controlled study. Lancet Neurol 2009;8:141-50.

28. Albers GW, Thijs VN, Wechsler L, Kemp S, Schlaug G, Skalabrin E, et al. Magnetic resonance imaging profiles predict clinical response to early reperfusion: The Diffusion and Perfusion Imaging Evaluation for Understanding Stroke Evolution (DEFUSE) Study. Ann Neurol 2006;60:508-17.

29. Davis SM, Donnan GA, Parsons MW, Levi C, Butcher KS, Peeters A, et al. Effects of alteplase beyond $3 \mathrm{~h}$ after stroke in the Echoplanar Imaging Thrombolytic Evaluation Trial (EPITHET): A placebo-controlled randomised trial. Lancet Neurol 2008;7:299-309.

30. Zangerle A, Kiechl S, Spiegel M, Furtner M, Knoflach M, Werner P, et al. Re-canalization after thrombolysis in stroke patients: Predictors and prognostic implications. Neurology 2007;68:39-44.

31. Ribo M, Alvarez-Sabin J, Montaner J, Romero F, Delgado P, Rubiera M, et al. Temporal profile of re-canalization after intravenous tissue plasminogen activator: Selecting patients for rescue reperfusion techniques. Stroke 2006;37:1000-4.

32. Furlan A, Higashida R, Wechsler L, Gent M, Rowley H, Kase C, et al. Intra-arterial prourokinase for acute ischemic stroke. The PROACT II study: A randomized controlled trial. Prolyse in Acute Cerebral Thromboembolism. JAMA 1999;282:2003-11.

33. The IMS Study Investigators. Combined intravenous and intraarterial re-canalization for acute ischemic stroke: The interventional management of stroke study. Stroke 2004;35:904-12.

34. Katz JM, Gobin YP, Segal AZ, Riina HA, et al. Mechanical embolectomy. Neurosurg Clin N Am 2005;16:463-74.

35. Leary MC, Saver JL, Gobin YP, Jahan R, Duckwiler GR, Vinuela F, et al. Beyond tissue plasminogen activator: Mechanical intervention in acute stroke. Ann Emerg Med 2003;41:838-46.

36. Smith WS, Sung G, Starkman S, Saver JL, Kidwell CS, Gobin YP, et al. Safety and efficacy of mechanical embolectomy in acute ischemic stroke: Results of the MERCI trial. Stroke 2005;36:1432-8.

37. Stead LG, Gilmore RM, Bellolio FM, Rabinstein AA, Decker WW. Percutaneous clot removal devices in acute ischemic stroke: A systematic review and meta-analysis. Arch Neurol 2008;65:1024-30.

38. Molina CA, Saver JL. Extending reperfusion therapy for acute ischemic stroke: Emerging pharmacological, mechanical, and imaging strategies. Stroke 2005;36:2311-20.

39. Smith WS, Sung G, Saver J, Budzik R, Duckwiler G, Liebeskind DS, et al. Mechanical thrombectomy for acute ischemic stroke final results of the multi MERCI trial stroke. 2008;39:1205-12.

40. Tomsick T, Broderick J, Carrozella J, Khatri P, Hill M, Palesch Y, et al. Revascularization results in the interventional management of stroke II trial. AJNR Am J Neuroradiol 2008;29:582-7.
41. Tomsick TA. Stroke odyssey. AJNR Am J Neuroradiol 2006;27: 2019-21.

42. Wahlgren N, Davalos A, Fieschi C, Ford GA, Grond M, Hacke W, et al. SITS Monitoring Study (SITS-MOST): A multinational multicentre monitoring study of safety and efficacy of thrombolysis in stroke. Final Study Protocol 2002. p. 12-18. Available from; http://www.acutestroke. org. [cited in 2002].

43. Davis SM, Donnan GA, Butcher KS, Butcher KS, Parsons M. Selection of thrombolytic therapy beyond $3 \mathrm{~h}$ using magnetic resonance imaging. Curr Opin Neurol 2005; 18:47-52.

44. Braaten JV, Goss RA, Francis CW. Ultrasound reversibly disaggregates fibrin fibers. Thromb Haemost 1997;78:1063-8.

45. Kondo I, Mizushige K, Ueda T, Masugata H, Ohmori K, Matsuo H Histological observations and the process of ultrasound contrast agent enhancement of tissue plasminogen activator thrombolysis with ultrasound exposure. Jpn Cire J 1999;63:478-84.

46. Suchkova V, Siddiqi FN, Carstensen EL, Dalecki D, Child S, Francis CW, et al. Enhancement of fibrinolysis with 40-kHz ultrasound. Circulation 1998;98:1030-5.

47. Alexandrov AV, Molina CA, Grotta JC, Garami Z, Ford SR, AlvarezSabin J, et al. Ultrasound-enhanced systemic thrombolysis for acute ischemic stroke. N Engl J Med 2004;351:2170-8.

48. Daffertshofer M, Gass A, Ringleb P, Sitzer M, Sliwka U, Els T, et al Transcranial low-frequency ultrasound-mediated thrombolysis in brain ischemia. Stroke 2005;36:1441-6.

49. Sharma VK, Venketasubramaniam N, Khurana DK, Tsivgoulis G, Alexandrov AV. Role of transcranial Doppler ultrasonography in acute stroke. Ann Ind Acad Neurol 2008;11:S39-51.

50. Cintas P, Nguyen F, Boneu B, Larrue V. Enhancement of enzymatic fibrinolysis with $2-\mathrm{MHz}$ ultrasound and microbubbles. J Thromb Haemost 2004;2:1163-6.

51. Porter TR, LeVeen RF, Fox R, Kriesfeld A, Xie F. Thrombolytic enhancement with perfluorocarbon-exposed sonicated dextrose albumin microbubbles. Am Heart J 1996;132:964-8.

52. Molina CA, Ribo M, Rubiera M, Montaner J, Santamarina E, Delgado-Mederos R, et al. Microbubble administration accelerates clot lysis during continuous 2-MHz ultrasound monitoring in stroke patients treated with intravenous tissue plasminogen activator. Stroke $2006 ; 37: 425-9$

53. Alexandrov AV, Mikulik R, Ribo M, Sharma VK, Lao AY, Tsivgoulis G, et al. A pilot Randomized clinical safety study of sonothrombolysis augmentation with ultrasound-activated perflutren-lipid microspheres $(\mu \mathrm{S})$ for Acute Ischemic Stroke. Stroke 2008;39:1464-9.

54. Soares BP, Chien JD, Wintermark M. MR and CT monitoring of re-canalization, reperfusion, and penumbra salvage everything that recanalizes does not necessarily reperfuse. Stroke 2009;40:2.

55. Puetz V, Dzialowskil I, Hill MD, Subramaniam S, Sylaja PN, Krol A, et al. Intracranial thrombus extent predicts clinical outeome, final infaret size and hemorrhagic transformation in ischemic stroke: the clot burden score. Int J Stroke 2008;3:230-6.

Accepted on 28-02-2009

Source of Support: Nil, Conflict of Interest: None declared. 